\title{
Twin Pregnancy with One Fetus and One Complete Mole - A Case Report
}

\section{Zwillingsschwangerschaft aus einem Fetus und einer kompletten Mole - ein Fallbericht}

Authors

Affiliations
A. Freis ${ }^{1}$, M. Elsässer ${ }^{2}$, C. Sohn ${ }^{2}$, H. Fluhr ${ }^{2}$

${ }^{1}$ Gynecological endocrinology and fertility disorders, University Hospital Heidelberg, Heidelberg, Germany

2 Gynecology and Obstetrics, University Hospital Heidelberg, Heidelberg, Germany
Key words

- gestational trophoblastic disease (GTD)

- multiple birth

- obstetrics

- pregnancy

Schlüsselwörter

- trophoblastäre Schwangerschaftstumoren

- Mehrlingsgeburt

- Geburtshilfe

- Schwangerschaft

Deutsche Version unter: http://dx.doi.org/ $10.1055 / \mathrm{s}-0042-109398$

\section{Abstract \\ $\nabla$}

Twin pregnancy consisting of one fetus and one complete mole (CMCF, complete hydatidiform mole and a coexistent fetus) is an obstetric rarity with an incidence of $1 / 22000$ to $1 / 100000$ pregnancies. Associated risks include prematurity, intrauterine death, vaginal bleeding, preeclampsia, hyperthyroidism, theca lutein cysts, uterine rupture and the development of malignant neoplasia in the form of a trophoblastic tumour (GTD, persistent gestational trophoblastic disease), which is thought to be the most common complication. We report the case of a 33-year-old patient diagnosed with CMCF in the 15th week of pregnancy. After comprehensive counselling the patient chose to proceed with her pregnancy under close observation and prophylactic fetal lung maturation. We were able to extend the pregnancy to 32 weeks gestation when heavy vaginal bleeding forced a decision to deliver by caesarean section.

\section{Case Report}

\section{$\nabla$}

A 33-year-old GII/P0 was examined at $14+2$ weeks gestation. In addtion to one eutrophic fetus with a normal placenta a second amniotic cavity with honeycomb-like structure was found $(60 \times 32 \mathrm{~mm})$, so that a diagnosis of CMCF was suspected ( Figs. 3 and 4). Metastases were excluded clinically.

The beta hCG level fell continuously from the 17th week of gestation onwards ( Fig. 1).

No signs of preeclampsia, HELLP syndrome or hyperthyroidism were detected under close observation.

\section{Zusammenfassung \\ $\nabla$}

Die Situation einer Zwillingsschwangerschaft, bestehend aus einem Fetus und einer kompletten Mole (CMCF, complete hydatidiform mole and a coexistent fetus) ist ein seltenes geburtshilfliches Ereignis und kommt in $1 / 22000$ bis $1 / 100000$ Schwangerschaften vor. Die Risiken hierfür umfassen Frühgeburtlichkeit, einen intrauterinen Fruchttod, vaginale Blutungen, Präeklampsie, Hyperthyreose, Thekaluteinzysten, Uterusruptur, und, als wohl größtes Risiko, die Entwicklung eines Trophoblastentumors als maligne Neoplasie (GTD, persisting gestational trophoblast disease). Wir berichten über eine 33-jährige Patientin, bei der wir in der 15. Schwangerschaftswoche die Diagnose einer CMCF gestellt haben. Die Patientin entschied sich nach ausführlicher Beratung für ein Fortführen der Schwangerschaft unter engmaschiger Vorsorge sowie Durchführung einer prophylaktischen Lungenreifung. Unter diesen Umständen konnten wir die Schwangerschaft bis in die 32. Schwangerschaftswoche verlängern, als uns starke vaginale Blutungen zur Entbindung via Sectio caesarea zwangen.

The suspected diagnosis was confirmed at caesarean section, which was performed without delay at $31+4$ weeks gestation in view of heavy vaginal bleeding most probably due to early premature placental abruption.

A male infant weighing $1900 \mathrm{~g}$ was delivered with Apgar scores of 7/8/9 at 1,5 and 10 minutes. Arterial $\mathrm{pH}=7.35$, venous $\mathrm{pH}=7.37$ and base excess was -0.4 ; decision-to-delivery time was $10 \mathrm{~min}$ utes. The pathology showed an almost completely necrotic hydatidiform mole (\$ Figs. 2 and 5) without evidence of choriocarcinoma. Maternal haemoglobin was $10.3 \mathrm{~g} / \mathrm{dl}$ postoperatively compared to a preoperative level of $13.2 \mathrm{~g} / \mathrm{dl}$. 


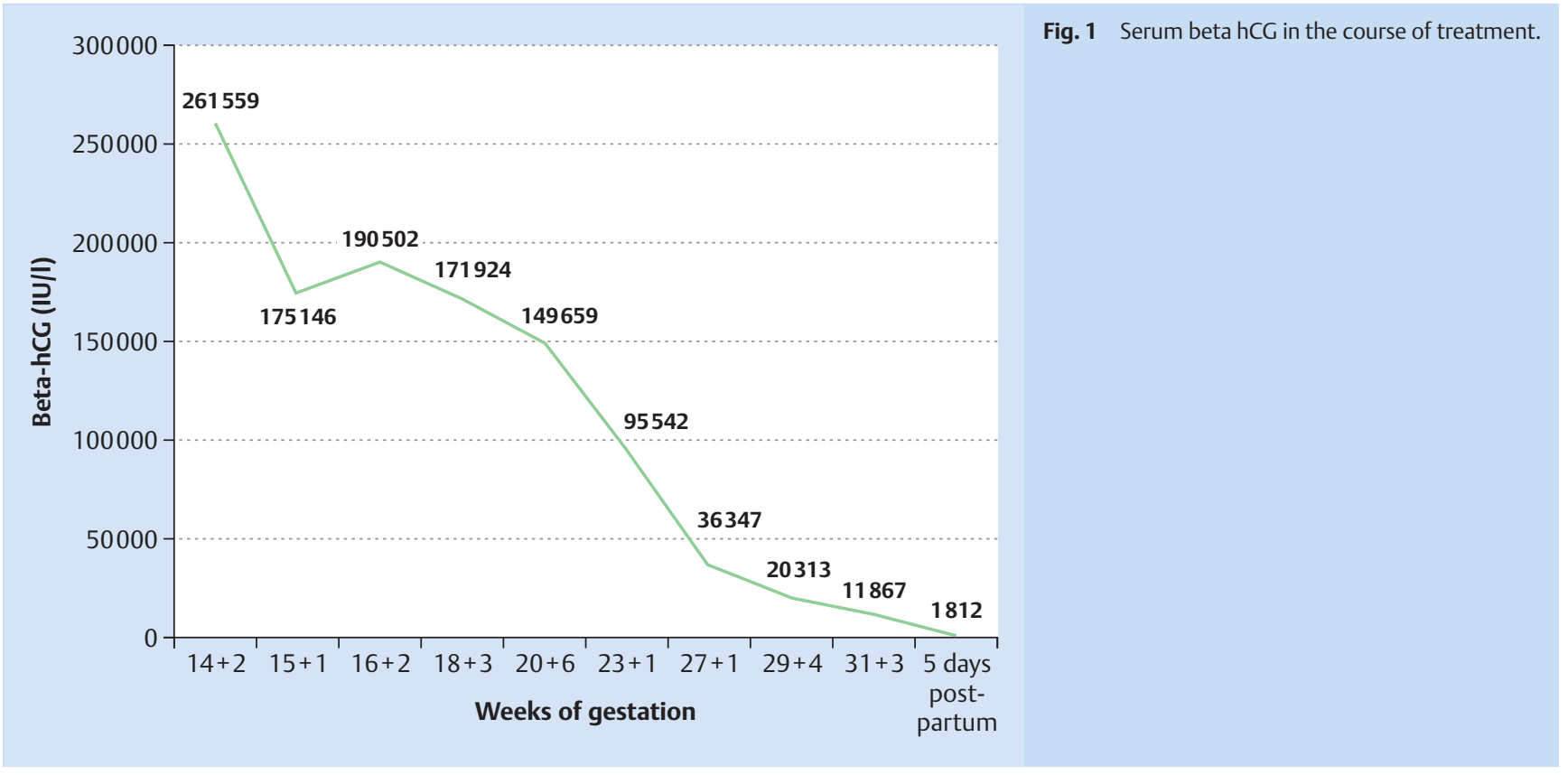

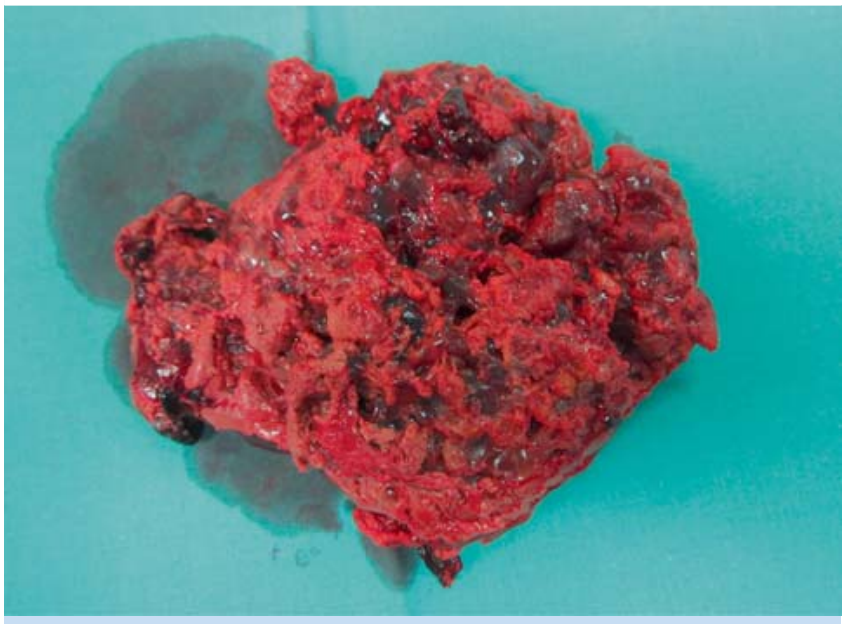

Fig. 2 Macroscopic picture of the hydatidiform mole.

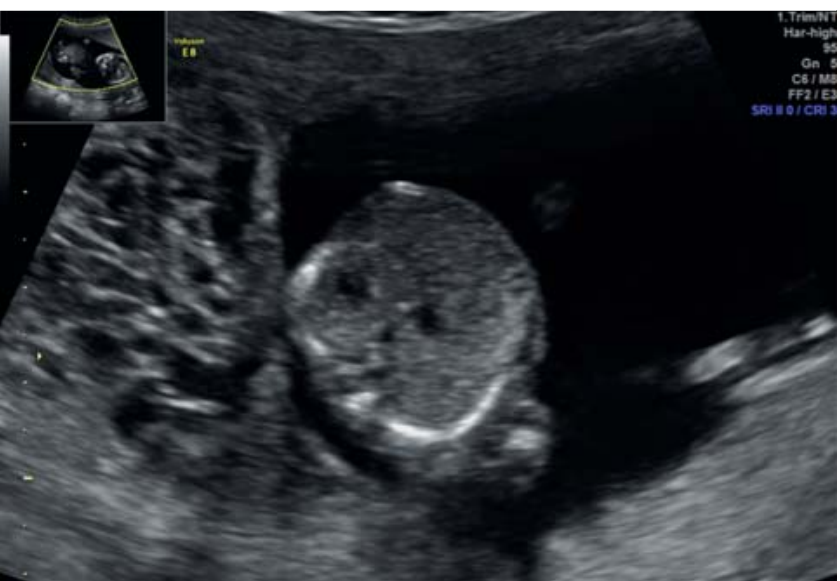

Fig. 3 Transverse sonographic view of the fetal abdomen adjacent to mole-like tissue.
An individualised follow-up schema was agreed on and at 2 months post partum a rise in serum beta hCG was noted. A repeat curettage was thus performed, the removed specimen showing only regressive placental villi without molar tissue.

A rising hCG level was again noted at 8 months post partum and this time two doses of methotrexate ( $1 \mathrm{mg} / \mathrm{kg} 14$ days apart) were administered. Despite this initial treatment serum hCG remained raised and a repeat curettage was performed. Choriocarcinoma was excluded on histology.

Under close observation serum hCG values have since remained undetectable.

\section{Discussion}

$\nabla$

Twin pregnancy consisting of one fetus and one complete mole (CMCF, complete hydatidiform mole and a coexistent fetus) is a rare occurrence in obstetrics with an incidence of $1 / 22000$ to $1 /$ 100000 pregnancies [1].

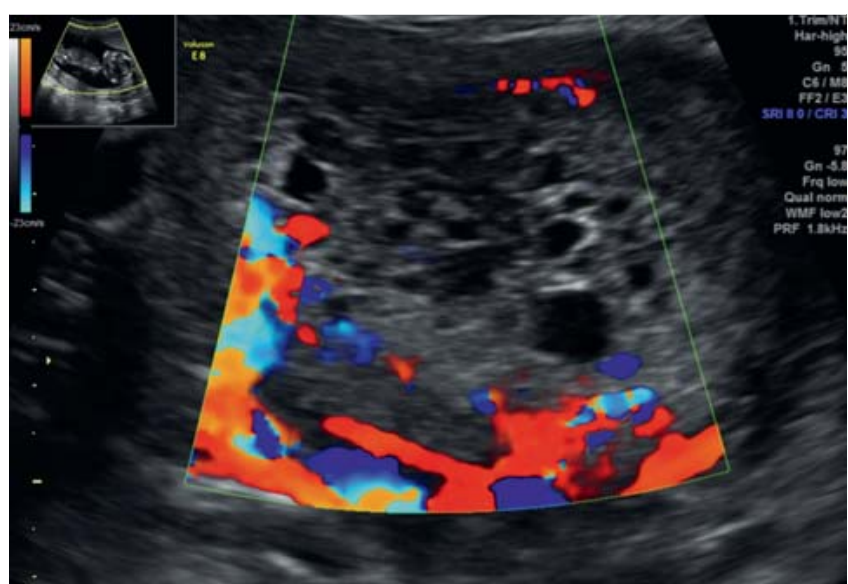

Fig. 4 Hydatidiform mole with reduced perfusion on Doppler ultrasound. 


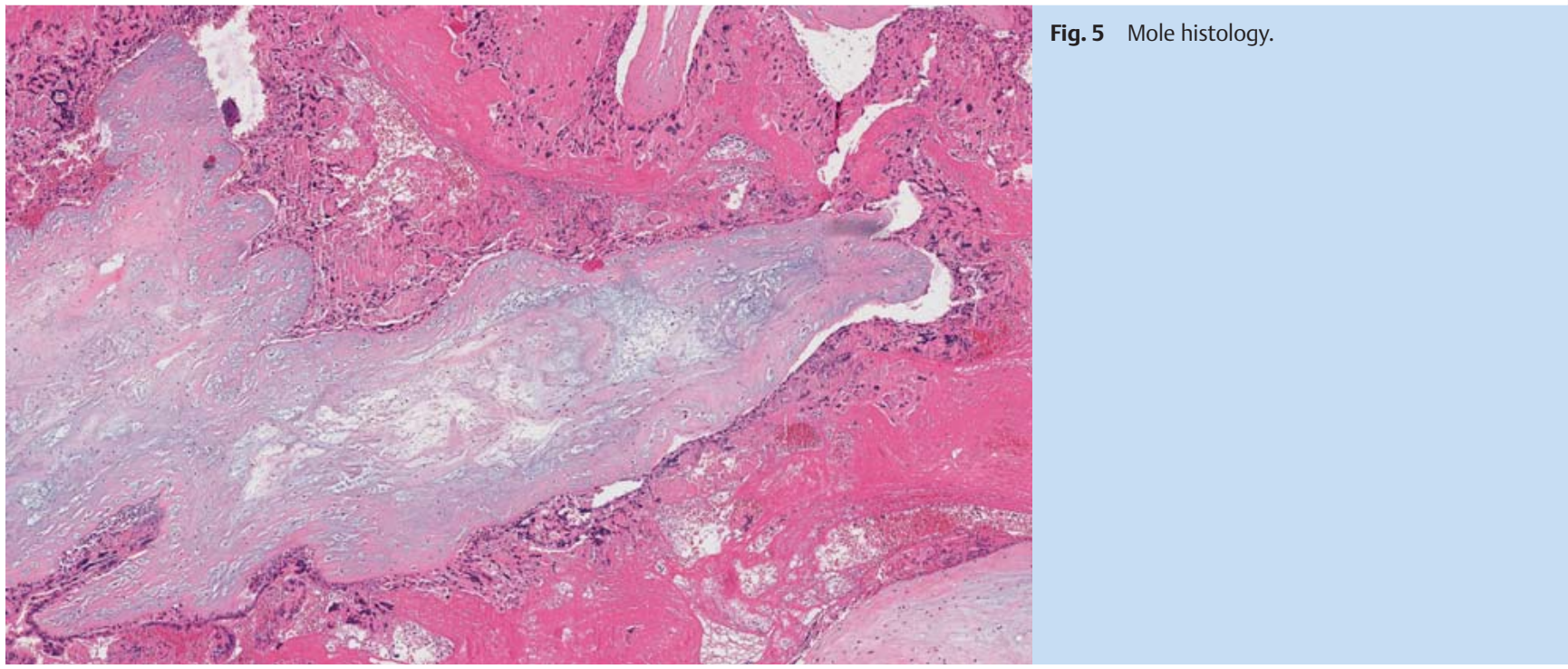

Diagnosis is mostly made on ultrasound, usually between the 12 th and 14th weeks of pregnancy [1,2], however despite advances in obstetric and gynaecological ultrasound the detection rate reported in the literature is only about 68\% [3]. MRI offers a useful imaging alternative $[4,12]$ and promising results have been published with the use of [18 F]fluorodeoxyglucose-positronemission-tomography in combination with CT [5].

A distinction is made between partial and complete moles. Partial moles contain a triploid set of chromosomes and are the result of dispermatic fertilisation of a haploid oocyte. Complete moles consist of 46 paternal chromosomes and do not have any fetal structures [3].

Three disease entities must be considered in the differential diagnosis when a mole-like placenta is suspected together with a viable fetus: a singleton pregnancy consisting of a partial mole and one viable fetus; a twin pregnancy with a complete mole and one viable twin with a separate placenta; and a combination of a partial mole with a twin in one amniotic sac, and one "normal" twin in the other [3].

When a partial mole is present the fetus involved is almost always triploid so that termination of pregnancy should be considered. On the other hand a diploid karyotype does not provide diagnostic certainty since diploid partial moles have been described [2].

Since the genotype origin of complete moles is entirely paternal the chromosomal origin should be determined. PCR techniques to detect DNA polymorphisms in molar tissue can show uniparental disomy either through exclusion of maternal alleles or on comparison with paternal alleles [2].

Continuation of pregnancy is possible when a complete mole together with a normal coexisting twin is diagnosed [3]. Such pregnancies are associated with increased risks of prematurity, intrauterine death, vaginal bleeding, preeclampsia, hyperthyroidism, theca lutein cysts, uterine rupture and the development of malignant neoplasia, i.e. a trophoblastic tumour (GTD, persistent gestational trophoblastic disease), which is thought to be the most common complication $[1,3,6]$.

Another important diagnosis to be considered in differential diagnosis is placental mesenchymal dysplasia, which, in contrast to molar pregnancies, carries no malignancy risk and, interestingly, is associated with Beckwith-Wiedemann syndrome in up to $25 \%$ of cases. Mesenchymal dysplasia is often characterised by dilated vessels and associated fetal growth restriction [7].

A possible explanation for the increased risk of vaginal bleeding is that molar implantation usually occurs in the lower uterine segment [8]. The risk factors for the occurrence of this disease entity have not yet been clearly defined although a number of studies report a disproportionately high number of twin pregnancies with complete mole and coexisting fetus (approx. 22\%) following reproductive medical intervention, e.g. ovarian stimulation $[1,3]$. When the pregnancy is not terminated the overall likelihood of a live birth is between 16 and 56\% [1,3]. Morocolles et al. put the live birth rate at $40 \%$ in the event of pregnancy being sustained beyond the 14th week of gestation [8], and Shaik et al., in a case report from 2015 , state a $40 \%$ probability of early pregnancy loss together with a $25 \%$ chance of a live birth [9]. In a comprehensive review from 2015 including 177 cases Rohilla et al. state a live birth rate of $37 \%$ [10].

On average children are delivered in the 30th week of gestation. When one considers all molar pregnancies together, termination of pregnancy occurs on average in the 16 th week [1].

The risk of developing GTD varies between 5 and 33\% [1,3] and is not increased significantly by continuation of pregnancy or reaching an advanced gestational age [3]. There is also no difference in GTD risk between complete mole without coexisting twin and the CMCF constellation [4,11].

The FIGO (Fédération Internationale de Gynécologie et d'Obstétrique) classification of GTD is essentially based on localisation (FIGO I: uterus; FIGO II: outside of the uterus but in the genital area; FIGO III: lungs; FIGO IV: all other localisations).

The modified, prognostically relevant scoring system incorporates the patient's age, the interval between current and previous pregnancy, the hCG level before commencement of treatment, tumour size, size and number of metastases and, if applicable, a history of previous unsuccessful chemotherapy [1].

In most cases GTD following CMCF can be adequately treated with monochemotherapy [1].

Free and total beta hCG levels are extremely high with a peak at the beginning of the 2nd trimester [8]. Alpha fetoprotein (AFP) is usually raised in patients with a complete mole but can be normal in the presence of $\mathrm{CMCF}$, whereas pregnancy-associated plasma protein A (PAPP-A) and pregnancy-specific beta 1 glyco- 
protein (SP1) are raised in both cases [2]. In our case PAPP-A and AFP levels were not determined in view of obvious laboratory and clinical findings.

Constant beta hCG monitoring is of clinical importance in order to assess the extent of the pathology and the associated risk of complications. In our case continuation of pregnancy was justified in the presence of continuously falling hCG levels from the 17 th week of gestation onwards.

In a large observational study including 77 patients with $\mathrm{CMCF}$ Sebire et al. reported termination of pregnancy in 10 cases before the 14th week, and in 5 cases between the 15th and 22nd weeks of gestation.

A further 2 of the 53 pregnancies that were initially continued were subsequently terminated before 24 weeks gestation due to early preeclampsia. 23 (43\%) patients had an abortion or an intrauterine fetal death before 24 weeks gestation. 28 women delived in or after the 24th week of gestation. In this group there were 20 (38\%) live births, 7 intrauterine deaths and one neonatal death.

Only one case of severe preeclampsia and one of pulmonary embolus were reported. Fifteen patients developed persistent GTD (19\%), and three of these patients terminated pregnancy within the first trimester. Eleven of these 15 patients were treated curatively with monochemotherapy (73\%) and 4 required combination chemotherapy [11].

\section{Clinical Bottom Line}

Twin pregnancy consisting of one fetus and one complete mole is a rare obstetric finding that presents a challenge to both the treating obstetrician and the patient and requires an open discussion of outcomes when deciding on a treatment strategy. The detection rate is low and doctors working in antenatal medicine in particular should be sensitised to the diagnosis to enable adequate assessment for possible risk factors such as premature birth, intrauterine death, vaginal bleeding, preeclampsia, hyperthyroidism, theca lutein cysts, uterine rupture and trophoblastic tumours. As this case illustrates, under close observation continuation of pregnancy can be considered.

\section{Conflict of Interest}

$\nabla$

None.

\section{References}

1 Massardier J, Golfier F, Journet D et al. Twin pregnancy with complete hydatidiform mole and coexistent fetus: obstetrical and oncological outcomes in a series of 14 cases. Eur J Obstet Gynecol Reprod Biol 2009; 143: 84-87

2 Wee J, Jauniaux E. Prenatal diagnosis and management of twin pregnancies complicated by a co-existing molar pregnancy. Prenat Diagn 2005; 25: 772-776

3 Vaisbuch E, Ben-Arie A, Dgani R et al. Twin pregnancy consisting of a complete hydatidiform mole and co-existent fetus: report of two cases and review of literature. Gynecol Oncol 2005; 98: 19-23

4 Himoto Y, Kido A, Minamiguchi S et al. Prenatal differential diagnosis of complete hydatidiform mole with a twin live fetus and placental mesenchymal dysplasia by magnetic resonance imaging J Obstet Gynaecol Res 2014; 40: 1894-1900

5 Mangili G, Bergamini A, Giorgione $V$ et al. [18F]fluorodeoxyglucose positron emission tomography/computed tomography and trophoblastic disease: the gynecologist perspective. Q J Nucl Med Mol Imaging 2016; 60: 103-116

6 Sánchez-Ferrer ML, Hernández-Martínez F, Machado-Linde F et al. Uterine rupture in twin pregnancy with normal fetus and complete hydatidiform mole. Gynecol Obstet Invest 2014; 77: 127-133

7 Starikov R, Goldman R, Dizon DS et al. Placental mesenchymal dysplasia presenting as a twin gestation with complete molar pregnancy. Obstet Gyecol 2011; 118: 445-448

8 Marcorelles P, Audrezet MP, Le Bris MJ et al. Diagnosis and outcome of complete hydatidiform mole coexisting with a live twin fetus. Eur J Obstet Gynecol Reprod Biol 2005; 118: 21-27

9 Shaik S, Al-Riyami N, Mathew NR et al. Twin pregnancy with a complete hydatidiform mole and a coexisting live fetus-rare entity. Sultan Qaboos Univ Med J 2015; 15: e550

10 Rohilla M, Singh P, Kaur J et al. Individualistic approach to the management of complete hydatidiform mole with coexisting live fetus. Eur J Obstet Gynecol Reprod Biol 2015; 191: 39-42

11 Sebire NJ, Foskett M, Paradinas FJ et al. Outcome of twin pregnancies with complete hydatidiform mole and healthy co-twin. Lancet 2002; 359: 2165-2166

12 Herek D, Karabulut $N$. The role of magnetic resonance imaging in the diagnosis of complete hydatidiform mole in a twin pregnancy. Int J Gynaecol Obstet 2013; 123: 77 